\title{
Komparasi Faktor Sosiodemografi Peserta Bali Biology Olimpiad Terhadap Nilai Bali Biology Olimpiad
}

\author{
Yustinus Victor Rianus Bura ${ }^{1.2}$, Dewa Ayu Puspawati ${ }^{1}$, Desak Nyoman Budiningsih ${ }^{2}$ \\ Program Studi Pendidikan Biologi, Fakultas Keguruan dan Ilmu Pendidikan, Universitas Mahasaraswati \\ Denpasar, Denpasar \\ victoryustinus@gmail.com
}

\begin{abstract}
Abstrak
Bali Biology Olimpiad (BBO) merupakan olimpiade biologi yang diselenggarakan oleh Himpunan Program Studi (HMPS) Pendidikan Biologi FKIP Universitas Mahasaraswati Denpasar, yang mengikut sertakan seluruh pelajar SMA se-Bali. BBO telah diselenggarakan sebanyak dua kali (2016 dan 2017)., peserta BBO berasal dari sekolah yang berbeda, ada yang berasal dari sekolah swasta dan ada yang berasal dari sekolah negeri (faktor sosial), selain berasal dari sekolah yang berbeda peserta olimpiade juga memiliki gender yang berbeda, ada laki-laki dan perempuan (faktor demografi). Berdasarkan observasi selama pelaksanaan BBO bahwa finalis BBO didominasi oleh perempuan selain itu penelitian atau evaluasi terhadap perbandingan faktor sosiodemografi peserta BBO terhadap nilai BBO belum pernah dilakukan, hal ini dijadikan dasar untuk melakukan penelitian lebih lanjut mengenai komparasi faktor sosiodemografi peserta BBO terhadap nilai BBO. Jenis penelitian yang digunakan adalah Ex-post Facto. Rancangan Penelitian Causal Comparative Research, waktu Penelitian dilaksanakan pada bulan Januari-Juni 2018. Hasil penelitian menunjukkan tidak ada komparasi faktor sosiodemografi peserta BBO terhadap nilai BBO, hal ini diperkuat dari hasil analisis Two Way Anova yang menunjukkan $\mathrm{F}$ hitung sebesar 0,226 dan nilai probabilitas nilai $\mathrm{BBO} 0,639>0,05$ sehingga hipotesis penelitian diterima dengan demikian dapat disimpulkan bahwa faktor sosiodemografi peserta BBO tidak berpengaruh terhadap nilai BBO.
\end{abstract}

Kata Kunci: BBO, Faktor Sosiodemografi, Two Way Anova

\section{Pendahuluan}

Pesatnya perkembangan ilmu pengetahuan dan teknologi hingga saat ini telah mengantarkan umat manusia ke era kompetisi global di berbagai bidang kehidupan. Situasi demikian menuntut kita agar segera berbenah diri dan sekaligus menyusun langkah nyata guna menyongsong masa depan. Salah satu program pemerintah dalam meningkatkan kualitas sumber daya manusia melalui Departemen Pendidikan Nasional adalah dengan menyelenggarakan Olimpiade Sains Nasional (OSN) di bidang Matematika, Fisika, Biologi, Kimia dan Informatika/Komputer (Kurniawati, 2011). Civitas Akademika Universitas Mahasaraswati Denpasar Fakultas Keguruan dan Ilmu Pendidikan Program studi pendidikan biologi sampai saat ini telah menyelenggarakan Bali Biology Olimpiad (BBO) sebanyak dua kali yang mengikut sertakan siswa siswi SMA dan SMP se-Bali, peserta BBO berasal dari sekolah yang berbeda, ada yang berasal dari sekolah swasta dan ada yang berasal dari sekolah negeri (sosial), selain berasal dari sekolah yang berbeda peserta olimpiade juga memiliki gender yang berbeda, ada laki-laki dan perempuan (demografi).

Perbedaan kemampuan khususnya daya serap antara laki-laki dan perempuan merupakan salah satu hal yang menarik untuk dibuktikan. Apalagi terdapat asumsi yang berkembang di tengah masyarakat bahwa anak laki-laki sebenarnya lebih pintar dibandingkan anak perempuan, hanya saja anak laki-laki itu pemalas, walaupun ternyata banyak juga yang berpendapat sebaliknya (Panji, 2011). Dalam 100 tahun terakhir, kata Flynn, IQ perempuan memang tertinggal sekitar 5 poin dibandingkan laki-laki. Tapi, kini jurang tersebut terhapus dan perempuan 
memimpin di depan (James Flyn dalam Candra, 2012). Maka, temuan ini memutarbalikkan 'pertempuran` gender yang kerap menempatkan laki-laki sebagai pemimpin dalam uji IQ.

Penelitian atau evaluasi terhadap perbandingan faktor sosiodemografi peserta BBO terhadap nilai $\mathrm{BBO}$ belum pernah dilakukan, hal ini dijadikan dasar untuk melakukan penelitian lebih lanjut mengenai komparasi faktor sosiodemografi peserta BBO terhadap nilai BBO HMPS Pendidikan Biologi FKIP Universitas Mahasaraswati Denpasar. Penelitian ini bertujuan untuk menganalisis komparasi faktor sosiodemografi peserta BBO terhadap nilai BBO HMPS Pendidikan Biologi FKIP Universitas Mahasaraswati Denpasar.

\section{Metode}

Jenis penelitian yang digunakan adalah Ex-post Facto. Rancangan Penelitian Causal Comparative Research Waktu Penelitian dilaksanakan pada bulan Januari-Juni 2018. Teknik sampling yang digunakan adalah sampling jenuh dimana sampel dari penelitian ini diambil dari populasi yang ada. Populasi dalam penelitian ini adalah nilai peserta BBO siswa-siswi SMA SeBali tahun 2017 sebanyak 26 daftar nilai peserta, 2 peserta laki-laki berasal dari sekolah negeri, 2 peserta laki-laki berasal dari sekolah swasta, 10 peserta perempuan dari sekolah negeri, 12 peserta perempuan dari sekolah swasta. Variabel bebas dalam penelitian ini adalah faktor sosiodemografi (gender dan status sekolah) siswa peserta BBO, sedangkan Variabel terikat dalam penelitian ini adalah nilai siswa peserta BBO. Pengumpulan data berupa nilai babak penyisihan BBO dari 26 siswa-siswi SMA Se-Bali yang telah ditabulasi oleh tim soal BBO tahun 2017. Daftar nilai peserta BBO kemudian dipilah atau dipisahkan berdasarkan status sekolah dan gender yaitu nilai BBO peserta didik perempuan dan laki-laki dari sekolah negeri dan nilai BBO peserta didik perempuan dan laki-laki dari sekolah swasta. Untuk menganalisis data dengan menggunakan analisis varian dua jalur (Two Way Anava).

\section{Hasil}

Data Analisis statistik deskriptif menunjukkan nilai peserta BBO bahwa dari 2 peserta BBO laki-laki berasal dari sekolah negeri memperoleh nilai lebih tinggi dibandingkan 2 peserta laki-laki dari sekolah swasta. Pada hasil analisis deskriptif nilai BBO dari 10 peserta perempuan dari sekolah negeri memperoleh nilai lebih tinggi dibandingkan nilai dari 12 peserta perempuan dari sekolah swasta. Untuk lebih jelas dapat dilihat pada Tabel 1.

Tabel 1. Analisis statistik deskriptif BBO berdasarkan faktor sosiodemografi

\begin{tabular}{ccccc}
\hline Gender & Sekolah & Mean & Std. Deviation & $\mathrm{N}$ \\
\hline \multirow{3}{*}{ Laki-laki } & Negeri & 90.00 & 39.59 & 2 \\
& Swasta & 57.00 & 18.38 & 2 \\
\multirow{3}{*}{ Perempuan } & Total & 73.50 & 31.59 & 4 \\
& Negeri & 57.20 & 31.11 & 10 \\
& Swasta & 38.75 & 24.84 & 12 \\
Total & Total & 47.13 & 28.75 & 22 \\
& Negeri & 62.66 & 33.13 & 12 \\
& Swasta & 41.35 & 24.33 & 14 \\
& Total & 51.19 & 30.13 & 26 \\
\hline
\end{tabular}


Dilihat dari gender peserta BBO, terdapat perbedaan antara nilai BBO peserta laki-laki dan perempuan. rata-rata nilai $\mathrm{BBO}$ peserta laki-laki lebih tinggi dibandingkan peserta perempuan. untuk lebih jelas hasil analisis disajikan pada Gambar 1.

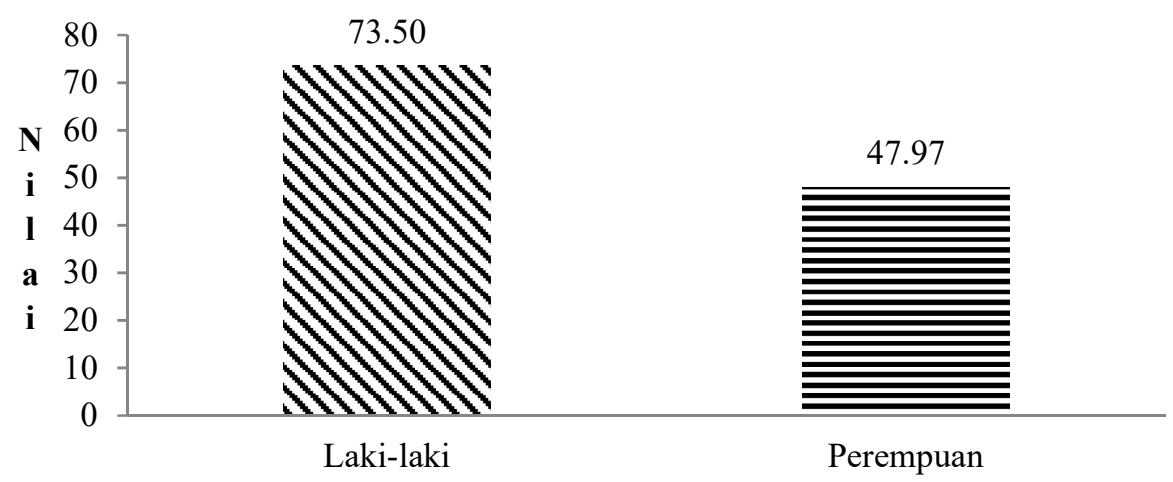

\section{Gambar 1. Nilai rata-rata peserta BBO berdasarkan gender}

Berdasarkan status sekolah peserta $\mathrm{BBO}$, terdapat perbedaan nilai rata-rata antara peserta BBO yang berasal dari sekolah negeri dan swasta, dimana nilai rata-rata peserta BBO dari sekolah negeri lebih tinggi dibandingkan dengan peserta $\mathrm{BBO}$ yang berasal dari sekolah swasta. Untuk lebih jelas dapat dilihat pada Gambar 2.

Gambar 2. Nilai rata-rata peserta BBO berdasarkan status sekolah

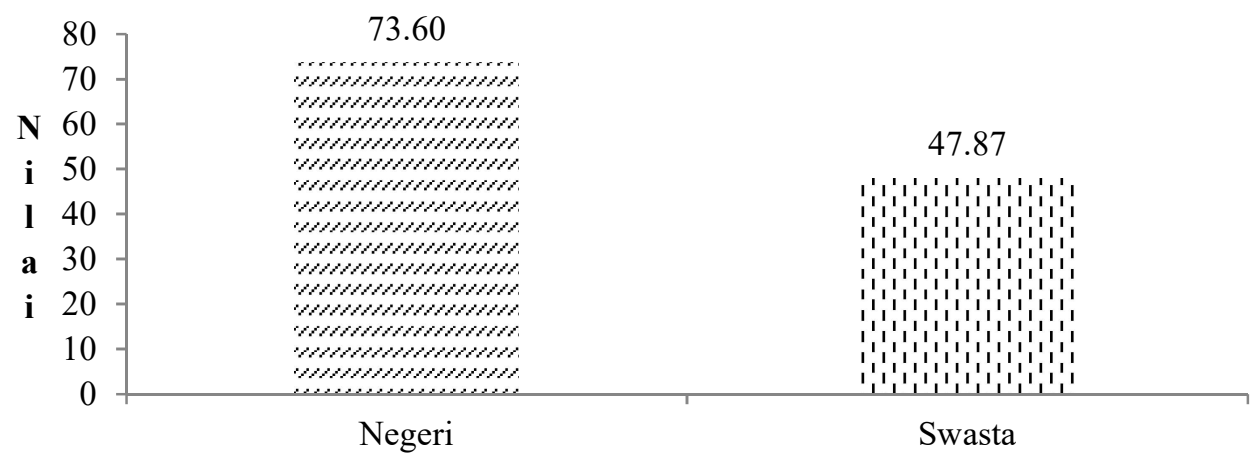

Berdasarkan hasil uji statistik dengan bantuan program komputer, dengan uji Anova dua jalur (Two Way ANOVA) menunjukkan tidak adanya komparasi antara semua variabel independen (gender, sekolah, dan interaksi gender dengan sekolah) secara bersamaan terhadap variabel dependen (nilai BBO) dengan taraf signifikansi sebesar 0,639>0,05 dan nilai determinasi berganda ( $R$ Square) sebesar 0,23 dimana belum mendekati 1 yang berarti korelasi antar variabel lemah. Untuk lebih jelas hasil analisis terdapat pada Tabel 2.

Tabel 2. Hasil uji Anova dua jalur faktor sosiodeografi terhadap nilai BBO

\begin{tabular}{lclll}
\hline \multicolumn{1}{c}{ Source } & Df & \multicolumn{1}{c}{ Mean } & F & Sig. \\
\hline Pengaruh semua variabel & 3 & 1766.063 & 2.232 & .113 \\
Perubahan Variabel & 1 & 49880.030 & 63.031 & .000 \\
Gender & 1 & 2202.340 & 2.783 & .109 \\
Sekolah & 1 & 2236.988 & 2.827 & .107 \\
Gender * Sekolah & 1 & 178.904 & .226 & .639 \\
Total & 26 & & & \\
\hline
\end{tabular}


Pengujian hasil hipotesis juga diperkuat dengan hasil perhitungan interaksi efek antar variabel yang di tunjukan diagram plot pada Gambar 3.

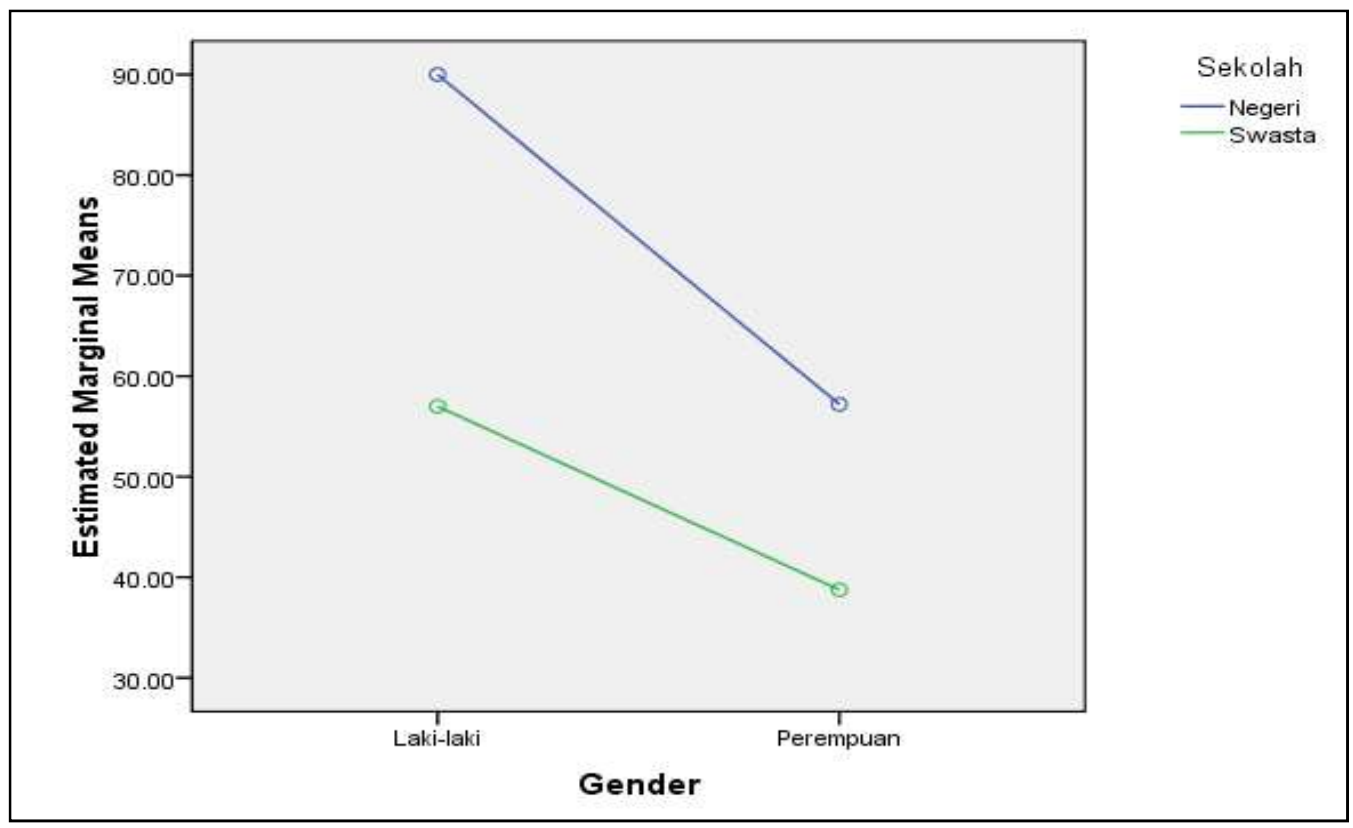

Gambar 3. Diagram Plot Sosiodemografi Terhadap Nilai BBO

Diagram plot diatas berguna untuk menunjukkan apakah ada interaksi antar variabel atau tidak, apabila garis-garis menunjukkan kesejajaran maka dicurigai tidak ada efek interaksi antar variabel. Berdasarkan hasil analisis diagram plot yang ditunjukkan pada Gambar 1.

\section{Pembahasan}

Hasil penelitian ini menunjukkan bahwa tidak ada perbandingan yang nyata antara faktor sosiodemografi peserta BBO dengan nilai BBO. Hal ini sejalan dengan penelitian sebelumnya Sugiarto (2007) menegaskan bahwa dalam hal kemampuan antara laki-laki dan perempuan sebenarnya tidak ada perbedaan yang esensial, tetapi perbedaan itu terletak pada sikap. Dalam penelitian yang lain Khorista (2014) mengungkapkan bahwa gender, status sekolah, dan wilayah sekolah tidak berpengaruh secara signifikan terhadap nilai hasil seleksi olimpiade nasional (OSN). Hasil penelitian tidak menunjukkan perbandingan nilai yang nyata antara peserta BBO laki-laki dari sekolah negeri dan peserta BBO laki-laki dari sekolah swasta. Hasil yang sama juga menunjukkan bahwa nilai rata-rata BBO peserta BBO perempuan dari sekolah negeri dengan peserta $\mathrm{BBO}$ perempuan dari sekolah swasta tidak ada perbandingan yang nyata antara keduanya.

Dari hasil perhitungan menggunakan diagram plot menunjukkan ada kesejajaran garis, maka ditarik kesimpulan bahwa tidak ada efek interaksi antar variabel atau dengan kata lain faktor sosiodemografi peserta BBO tidak berpengaruh secara signifikan terhadap nilai BBO. Hasil penelitian ini senada dengan penelitian Nurmaliah (2010) yang mengemukakan bahwa gender bukanlah faktor yang menentukan keterampilan metakognitif yang akan berpengaruh pada prestasi peserta didik. Hal ini diperkuat oleh Mongi (2016) dalam penelitiannya yang berjudul perbandingan SMA negeri dan SMA swasta berdasarkan nilai akreditasi dan nilai ujian nasional menggunakan uji-t di kota Manado mendapatkan hasil yang serupa, bahwa tidak ada perbedaan yang signifikan antara jenis sekolah, nilai akreditasi dan nilai ujian nasional.

Berdasarkan penelitian yang dilakukan ada beberapa kelemahan dalam penelitian ini antara lain: 1) jumlah sampel yang digunakan masih terlalu sedikit, sehingga bisa saja terpengaruh 
pada hasil penelitian yang kurang maksimal, 2) sedikitnya variabel sosiodemografi yang digunakan sehingga hasil penelitian belum menunjukkan hasil yang cukup akurat terutama dari segi waktu pelaksanaan BBO, 3) kurangnya referensi terkait dengan penelitian serupa sehingga menyulitkan pencarian pustaka dan lemahnya relefansi penelitian.

\section{Simpulan}

Berdasarkan hasil analisis yang didapatkan, maka dapat diambil kesimpulan bahwa nilai BBO tidak berpengaruh terhadap status sekolah ataupun gender peserta BBO.

Adapun saran yang dapat diberikan setelah melakukan penelitian ini adalah sebagai berikut:

1. Dalam melakukan penelitian lanjutan agar dapat menggunakan sampel yang lebih banyak lagi agar penelitian ini dapat berpengaruh pada hasil yang maksimal

2. Faktor sosiodemografi yang digunakan dalam penelitian terlalu sedikit sehingga penelitian kurang maksimal, faktor sosiodemografi sebaiknya ditambah lagi seperti faktor usia, jenjang pendidikan peserta BBO, hingga rentang waktu pelaksanaan BBO tahun 2016 dan 2017.

\section{Ucapan Terimakasih}

Ucapan terimakasih penulis sampaikan kepada pihak-pihak yang telah berkonstribusi selama penelitian, kepada Dosen pengampu mata kuliah Tata Tulis Artikel Ilmiah Bapak Prof. Dr. Sang Putu Kaler Surata, M.S yang telah membina, memberikan kritik dan saran dalam penulisan artikel. Ucapan terimakasih juga penulis sampaikan tim evaluasi artikel Semester VII Biologi angkatan 2014 yang telah mengevaluasi, mengkoreksi, mengkritik serta memberikan saran yang membangun dalam penyelesaian penulisan artikel.

\section{Referensi}

Candra, A. (2012). IQ wanita di negara maju lebih tinggi dari pria. diakses pada 21 Februari 2018 . dari: https://lifestyles.kompas.com/read/2012/07/16/11594968/IQ.Wanita.di.negara.maju.lebih.ti nggi.dari.pria\&grqid $=\mathrm{q} 4 \mathrm{ormpc} Y \& \mathrm{~s}=1 \& \mathrm{hl}=\mathrm{id}-\mathrm{ID}$

Khoirista, N. R., H. Suwono., A. Witjoro. (2014). Perbedaan Sikap Siswa Terhadap Pelajaaran Biologi Berdasarkan Gender, Status Sekolah, Wilayah Sekolah dan Hubungannya Terhadap Hasil Belajar Biologi. Universitas Negeri Malang, Malang.

Kurniawati, M. (2011). Kajian Motivasi Belajar Mandiri Siswa melalui Pembinaan dan Pendampingan Olimpiade Sain Nasional (OSN) Bidang Kimia pada Siswa SMA. Jurnal inspirasi pendidikan Universitas Kanjuruhan Malang. 3(2). 446-455

Mongi, C. E., D. Hatidja. (2016). Perbandingan Sma Negeri Dan Sma Swasta Berdasarkan Nilai Akreditasi Dan Nilai Ujian Nasional Menggunakan Uji-t Di Kota Manado. Jurnal Ilmiah Sains. 16(2). 91- 97.

Nurmaliah, C. (2010). Analsis keterampilan metakognitif siswa SMP negeri di kota Malang berdasarkan kemampuan awal, tingkat kelas, dan jenis kelamin. Jurnal Syiah Kuala University Darusalam Banda Aceh.

Panji, I. (2011). Sekolah Negeri dan sekolah swasta tangan kanan dan tangan kiri. diakses pada 21 Februari 2018. diunduh dari: https://panjiirfan.worpress.com/2011/05/25/sekolah-negeridan-sekolah-swasta-tangan-kanan-dan-kiri/ 
Sugiarto. (2007). Perbedaan Hasil Belajar Membaca Antara Siswa dan Siswi. http://infosiswa.blogspot.com/2007/06/perbedaan-hasil-belajar-membacaantara.html. Diakses 8 Juni 2018 